May 2020

\title{
"It's Not Like He Was Being a Robot:" Student Perceptions of Video-Based Writing Feedback in Online Graduate Coursework
}

David T. Marshall

Auburn University, dtm0023@auburn.edu

Savanna M. Love

Randolph-Macon College, savannalove@rmc.edu

LaRon Scott

Virginia Commonwealth University, scottla2@vcu.edu

Follow this and additional works at: https://digitalcommons.georgiasouthern.edu/ij-sotl

\section{Recommended Citation}

Marshall, David T.; Love, Savanna M.; and Scott, LaRon (2020) "'It's Not Like He Was Being a Robot:" Student Perceptions of Video-Based Writing Feedback in Online Graduate Coursework," International Journal for the Scholarship of Teaching and Learning: Vol. 14: No. 1, Article 10.

Available at: https://doi.org/10.20429/ijsotl.2020.140110 


\title{
"It's Not Like He Was Being a Robot:" Student Perceptions of Video-Based Writing Feedback in Online Graduate Coursework
}

\begin{abstract}
Although much research has explored the impact writing feedback has on student learning, it has primarily focused on undergraduate coursework offered in traditional face-to-face settings. This work explores student perceptions of writing feedback they received in an online graduate-level research methods course. Using a seven-point framework based on undergraduate writing feedback literature, students received feedback on a semester-long research proposal writing project. We explored student perceptions of the feedback they received in both written and video formats. Interviews were conducted with participants in both studies to understand their perceptions of the feedback they received. Students perceived the feedback and revision process as being constructive, positively impacting their content knowledge about the research process, and as facilitating their growth as writers for research. Most participants preferred the video-based feedback they received. This was found to impact the relationship students formed with the instructor in the course and support student growth as writers for research.
\end{abstract}

\section{Keywords}

writing feedback; video-based feedback; asynchronous video; instructor social presence

\section{Creative Commons License}

c) (i) $९$

This work is licensed under a Creative Commons Attribution-Noncommercial-No Derivative Works 4.0 License. 
IJ-SoTL, Vol. 14 [2020], No. 1, Art. 10

\title{
"It's Not Like He Was Being a Robot:" Student Perceptions of Video-Based Writing Feedback in Online Graduate Coursework
}

\author{
David T. Marshall', Savanna M. Love², and LaRon Scott ${ }^{3}$ \\ ' Auburn University \\ ${ }^{2}$ Randolph-Macon College \\ ${ }^{3}$ Virginia Commonwealth University
}

Received: 20 August 2019;Accepted: 6 March 2020

\begin{abstract}
Although much research has explored the impact writing feedback has on student learning, it has primarily focused on undergraduate coursework offered in traditional face-to-face settings. This work explores student perceptions of writing feedback they received in an online graduate-level research methods course. Using a seven-point framework based on undergraduate writing feedback literature, students received feedback on a semester-long research proposal writing project. We explored student perceptions of the feedback they received in both written and video formats. Interviews were conducted with participants in both studies to understand their perceptions of the feedback they received. Students perceived the feedback and revision process as being constructive, positively impacting their content knowledge about the research process, and as facilitating their growth as writers for research. Most participants preferred the video-based feedback they received. This was found to impact the relationship students formed with the instructor in the course and support student growth as writers for research.
\end{abstract}

\section{INTRODUCTION}

Empirical researchers have consistently found feedback to play an important role in student learning (see, e.g., Agius \& Wilkinson, 20 I4; Hattie, 2009; Rowe, 20I I). For example, feedback has been tied to the process of understanding (Agius \& Wilkinson, 20I4; Rowe, 20I I), and to increases in student learning across a variety of contexts (e.g. Hattie \& Timperley, 2007). Feedback can also serve as a form of academic interaction and encouragement (Rowe, 20 I I; Sommers, 2006). However, as Hattie's (20I2) research suggests, "there is as much ineffective as effective feedback" out there (p. 18). While researchers consistently study the impact feedback can have, not as much is known about student perceptions of the feedback they receive. Writing feedback is most commonly given in the form of written comments from the instructor, which the student then reads and interprets on their own. How students perceive the feedback they receive can be a critical factor in determining how and to what extent a student learns from the feedback given (Ryan \& Henderson, 2018). It is therefore important to investigate student perceptions of writing feedback in order to better understand how to engage students in this context.

\section{Writing feedback}

In addition to its overall beneficial role in learning, feedback has also been linked to supports for writing success. Researchers of writing feedback have examined the focus and form of teacher written commentary, teacher-student writing conferences, and questions related to error corrections or written corrective feedback (Ferris, Liu, Sinha, \& Senna, 20 I 3; see Ferris, 2003; Goldstein, 2004; Liu \& Hansen, 2002 for reviews on this). Early studies of teacher feedback indicated that teachers focused predominantly on language errors in student writing (e.g. Cumming, 1985) due to the fact that writing was treated primarily as a product (Ferris, 2003). As writing instruction shifted to focus more on process approaches, results of studies showed a shift from form to other issues such as content and organization (e.g. Crookes, Davis, \& Caulk, 1994; Conrad \& Goldstein, 1999). For example, in Ferris' (1997) study, I5\% of teacher comments were found to focus on grammar and mechanics, while $85 \%$ addressed students' ideas and rhetorical development.

A considerable amount of the writing feedback research to date focuses on error correction, exploring the type and extent of error feedback and its impact on student accuracy (Lee, 2008). Strategies for error correction include direct and/or indirect feedback. Direct feedback is given when teachers provide correct answers in response to student errors and indirect when teachers indicate an error by means of a code or mark (e.g. circling, underlining, etc.). Indirect feedback can be coded or uncoded, meaning the type of error is indicated (e.g. "tense") or not indicated (i.e. simply underlining the error) (Ferris, 2003; Ferris, 20I4; van Beuningn, de Jong, \& Kuiken, 2008). Some empirical studies have found indirect feedback to be more beneficial to students' longterm writing development (Ferris, 2003, 20I4), and that coded indirect feedback is most useful when it is part of consistent, systematic grammar instruction (Ferris, 2003). An experimental study conducted by van Beuningen, de Jong, and Kuiken (2008) found the opposite to be true; only direct feedback had a significant long-term effect on writing accuracy. Study results have also provided evidence that selective error feedback is more productive than correcting all errors, as comprehensive error feedback can be overwhelming for both student and teacher (Ferris, 2003; Mantello, 1997).

The form and function of teachers' written comments has also been highlighted in the literature on writing feedback (Ferris, 2003; Hyland \& Hyland, 200 I). Findings from seminal research indicated that teacher comments were mostly vague, non-text specific and mostly negative (Cumming, 1985; Zamel, 1985), and Lee (2008) posited that teachers appeared to "wear the hat of an evaluator judging student papers more or less in a vacuum" (p. 7I). More recent studies have shown a shift away from the decontex- 
tualized approach to written commentary, with teachers taking into account student characteristics and institutional requirements and attempting to build relationships with students through written commentary (Goldstein, 2004; Hyland \& Hyland, 200 I) These results of these studies help demonstrate the importance of providing clear, concrete, text-specific comments, including both praise and constructive criticism, and engaging with students and building relationships with them (Goldstein, 2004; Hyland \& Hyland, 200I).

\section{Student perceptions of writing feedback}

Much of the work on feedback perceptions to date focuses on feedback students have received generally, as opposed to feedback on written work specifically (Higgins et al., 200I; Holmes \& Papageorgiou, 2008; Rowe, 20I I; Weaver, 2006). For example researchers have explored how students use feedback (Poulos \& Mahony, 2008), students' preferences for receiving feedback (Rowe, 20I I), barriers to the utility of feedback (see, e.g., Higgins et al., 200I; Poulos \& Mahony, 2008), and differences in perceptions of feedback between students and instructors (see, e.g., Holmes \& Papageorgiou, 2008; Price, Handley, Millar, \& O'donovan, 20 I0).

Findings from these studies mostly demonstrate that students often find written feedback to be unhelpful, some describing it as illegible, too vague and impersonal (Higgins et al., 200 I), while others discuss how the feedback they receive is generally lacking in guidance or too focused on negative aspects (Weaver, 2006) Findings also suggest that what instructors perceive as helpful feedback differs from students' ideas of helpful feedback (Carless, 2006), with college students perceiving effective feedback as that which is encouraging, demonstrates instructor engagement, and has clear suggestions for improvement (Lizzio \& Wilson, 2008).

Researchers have also reported that although students recognize feedback as a means to improve their learning (Holmes \& Papageorgiou, 2008) and acknowledge reading feedback they receive (Higgins et al., 200 I; Orsmond, Merry, \& Reiling, 2005), they do not fully utilize the feedback they receive (Li \& De Luca, 20I4). One of the barriers to the usefulness of feedback may be related to students' tendency to focus on grades rather than on comments (e.g., Carless, 2006). Other feedback may be so specific to a particular assignment that the feedback is not easily transferable to other assignments (Carless, 2006). Therefore, although students seem to be aware of the educational benefits of feedback, the feedback students actually received is not always perceived as helping students to learn at the college level.

\section{Writing feedback in face-to-face and online settings}

Providing students feedback on their writing differs in face-to-face and online settings (Laflen \& Smith, 20I7;Wolsey, 2008). In traditional face-to-face classroom settings, instructors and learners also learn from non-verbal cues, informal conversations before and after class, small group activities, and one-on-one conferences. Online settings rely on mostly text-based interactions between students and instructors, and written feedback on assignments plays a greater role in the learning process (Laflen \& Smith, 20I7). Hybrid, blended learning environments offer instructors opportunities to supplement a primarily text-based, online learning environment with some of the additional modes of communication found in traditional settings, and a review of the literature on teaching academic writing in higher education settings found this to be more effective than in online-only settings (Scott, Ribeiro, Burns, Danyluk, \& Bodnaresko, 2017). One issue of concern for providing writing feedback in online and hybrid settings highlighted in the literature is the amount of work that providing sound, iterative writing feedback places on the instructor (Scott et al., 20I7;Wijeyewardene, Patterson, \& Collins, 20I3). Because online instruction lacks the informal, interpersonal interaction between instructors and learners, more care needs to be given to the written feedback that is given, especially for assignments involving academic writing.

\section{Audio and video feedback}

An increased interest in online learning environments has led to ongoing discussions about the effectiveness of various forms of feedback students receive throughout an online course. Traditionally, feedback has come in the form of written comments on assignments. Research has shown that personalized feedback messages in online courses have a positive association with student satisfaction and academic performance (Pardo, Jovanovic, Dawson, Gasevic \& Mirriahi, 2019). Thus, finding approaches to provide personalized, high quality feedback has become and important area of consideration for online environments. Recent literature has established that audio and video feedback has the ability to convey the non-verbal immediacy cues necessary to create closeness and increase social presence (Borup et al., 20l4). Researchers investigating asychoronous audio feedback define it as providing audio feedback or comments in response to student work (e.g. Oomen-Early, Bold,Wiginton, Gallien \& Anderson, 2008). In general, students report that they enjoy hearing their instructor's voice through audio feedback (Wallace \& Morre, 20I2) and that audio feedback feels more supportive, interactive and personal (e.g. Gould \& Day, 20I3;Thompson \& Lee, 20I2) Overall, the research surrounding audio feedback implies that it can be advantageous in establishing connections with students as well as supporting students through the learning process (Lowenthal, 20I5). Instructors who use video feedback generally do so under the assumption that the visual nature of the feedback will extend the advantages of audio feedback (Thomas, West \& Borup, 2017). Specifically, research has demonstrated the ways in which asynchronous, one-to-one, video feedback is advantageous to building student-teacher relationships, with students claiming that watching video feedback felt personal (e.g. Borup et al., 20I4), like the instructor knew them (Parton, Crain-Dorough, \& Hancock, 20l0), cared about them, (Henderson \& Phillips, 20I5) and valued them (Harper, Green, \& Fernandez-Toro, 20I2). Students have also reported that it was easier to understand their instructor through video than through text (e.g. Borup, West \& Thomas, 20I4; Parton et al., 20l0), and that video feedback made instructors feel more real, which motivated them to compelte assignments (Borup et al., 20 I4; Harper et al., 20 I2; Henderson \& Phillips, 20I5). Instructors also reported that it was easier to give encouragement and communicate authentically with the students in video feedback as opposed to text comments (Harper et al., 20I2).

Though the percetions of video feedback have been largely positive, students have also reported some potential drawbacks. Some students reported feelings anxious to watch their video feedback, while others discussed finding it difficult to contextualize their video feedback comments within their written projects (Henderson \& Phillips, 2015). Additionally, some students were found to be more likely to respond to text feedback due to its 
convenience (Borup et al., 20I4), while others reported that they preferred video feedback to text feedback but found it more time consuming to download (McCarthy, 20I5).

Therefore, it is important to continue to investigate student perceptions of video feedback to fully understand the impacts it may have on student engagement and instructor relationships. Understanding the influence asynchronous video feedback has on student perceptions of student-teacher relationships may help instructors facilitate online and blended learning environments thst support a sense of classroom community and encourage student engagement and cognitive presence (Collins, Groff, Mathena, \& Kupczynski, 2019).

A lot of scholarship has explored the relationship between feedback and writing outcomes, student perceptions of feedback, and the utility of the feedback that is received on writing assignments. Additionally, new trends in research have begun to focus on how to create successful online learning environments and on the impact audio or video feedback methods have may have on establishing those environments. However, this research has overwhelmingly been conducted on undergraduate students learning in traditional face-to-face classroom settings. Little work has explored writing feedback and asynchronous video feedback in graduate-level coursework or coursework that takes place in hybrid or online settings. There is also a lack of literature exploring student perceptions of feedback on writing related to graduate level research. This study contributes to the literature by exploring student perceptions of writing and video feedback in a hybrid, graduate-level research methods course.This study sought to answer the following questions:

\section{To what extent do students' perceptions of the feedback they received differ based on the type of feedback they received?}

\section{To what extent did students feel that the feed- back they received impacted their growth as writers?}

\section{CONTEXT}

The work that is described here was carried out during the Fall 2015 and Fall 2016 semesters and examined student perceptions of writing feedback in a graduate-level education research methods course. The study took place at a large public university located in a mid-sized city in the Mid-Atlantic region of the United States. The course was predominantly taught online with three optional face-to-face meetings during the semester. All students enrolled in the course were local, and more than three-fourths of students attended these sessions. The aim of the course was to teach students who had little experience with research the process of conducting research in the social sciences. Most of the students enrolled in the course would not go on to do research themselves. However, a major goal of the course was to equip students with the tools to be able to consult the literature to further their professional practice and to do so with a critical eye.

In this study, we sought to understand how students in a graduate-level research methods course perceived the feedback they received on their writing with two aims in mind. First, we hoped that what we would find would elevate our own teaching practices. Second, we hoped that what we learned as a result of this work would add to the larger knowledge base on how students respond to feedback, especially in graduate-level and non-traditional settings.

\section{METHODS}

A qualitative, descriptive design was adopted to explore student perceptions of writing feedback. The primary deliverable for the course was a research proposal that was designed individually by students and constructed over the course of the semester. The proposal required students to: (I) come up with a topic of interest; (2) conduct a brief literature review; (3) craft specific research questions; (4) develop a methodology to answer the research questions; (5) develop an appropriate data analysis approach; and (6) identify limitations associated with the proposed study. Students were not required to carry out the study; such a requirement would have been beyond the scope of the course's aim, which was to introduce graduate students who were not researchers to the research process. Students submitted the research proposal in three parts. The first part included an introduction, literature review, and research questions. The second part outlined the methodology, and the third part described the data collection procedures and data analysis approach, as well as potential limitations associated with the proposed study. This study was carried out over the course of two semesters. During the first iteration of the course, all participants received written feedback on each part of their papers. In the second iteration, participants received written feedback on the first part of their proposal and received video-based feedback on the second and third parts of their proposal. The feedback students received most commonly involved course content and its application to their paper's topic and APA formatting. Papers received feedback around grammatical errors when needed as well.

The written feedback was given digitally in the form of comments made in the margins of Microsoft Word documents, as well as comments made in an embedded rubric in the course's learning management system. The comments made by the instructor addressed a rubric that students were given at the start of the semester. On average, papers receiving written feedback took approximately 20 minutes to grade. Papers receiving video-based feedback received considerably less written feedback. Here, the written comments that were provided served as markers for portions of the paper that were discussed in the video-based feedback.Videos were between 5 and 10 minutes in length, with an average of six and a half minutes, and papers graded using video-based feedback took approximately 25 minutes to grade, including the time it took to record the video. By the end of the semester, video-based feedback times improved, although these papers still tended to take a little longer to grade than those that only received written feedback.

The feedback given in the videos was not scripted prior to recording; however, the videos were based on individualized talking points that were developed during the grading process. As such, the volume of comments found in a paper that received video-based feedback was substantially less than a paper that received only written feedback since many of the comments were covered in the video-recorded dialogue instead.Videos were recorded in the instructor's university office on his MacBook using QuickTime version 10.5 and were subsequently posted online so that only the student could access through a password-protected website. No grades were discussed in the videos to ensure compliance with the Family Educational Rights and Privacy Act 
of I 974, better known to most Americans as FERPA.All students were allowed to revise each section once to improve their writing product and their grade.

We created and used a seven-point framework for providing feedback on the research proposal assignment based on our review of the literature which explained that feedback should: (I) include both positive and critical feedback (e.g. Ferris, 20I4); (2) be specific (e.g. Sommers, 2006); (3) be timely (e.g. Holmes and Papageorgiou, 2008); (4) be aligned with assessment criteria (e.g Wood, 20I2); (5) be related to the assignment (Weaver, 2006); (6) be developmentally focused (e.g. McGrath, Taylor, \& Pychyl, 20 I I); and (7) be paired with opportunities for revision (e.g. Myhill \& Jones, 2007).A checklist including these seven items was created and completed for each paper that was graded during both semesters to help ensure consistency and adherence to this framework.

\section{Participants}

The participants were selected using purposive sampling (Mertler, 2018). The university at which this study takes place enrolls over 30,000 students, one in three of which are underrepresented minority students. All students enrolled in the instructor's graduate research methods course from both semesters were invited to participate in the study. Most of the students enrolled in the course were pre-service special education teachers who were part of a program that sought to train teachers for the urban school district in the city in which the university resides. Almost all of the remainder of the students were enrolled either in master's level counselor education or educational leadership programs. For the special education and counselor education students, this course represents the only research course in their programs of study. Overall, I I students agreed to participate in the study. See Table I for a breakdown of the students enrolled in the course over the two semesters.

\begin{tabular}{|l|l|l|l|}
\hline Table I. Students Enrolled in the Research Methods Course \\
\hline & 2015 & 2016 & Total \\
\hline Total & 15 & II & 26 \\
\hline Gender & & & \\
\hline Female & II & 7 & 18 \\
\hline Male & 4 & 4 & 8 \\
\hline Race/Ethnicity & & & \\
\hline African American & 9 & 3 & 12 \\
\hline Latino/a & 2 & 0 & 2 \\
\hline White & 3 & 7 & 10 \\
\hline Other & 1 & 1 & 2 \\
\hline Program & & & \\
\hline Special Education & 9 & 8 & 17 \\
\hline Counselor Education & 3 & 0 & 3 \\
\hline Educational Leadership & 0 & 3 & 3 \\
\hline Other & 3 & 0 & 3 \\
\hline
\end{tabular}

Data were collected through semi-structured interviews. Interview questions probed for implementation of the writing feedback framework and student perceptions of the feedback that they received. Interviews were between 15 and 30 minutes in length and were audio recorded and transcribed verbatim. See Appendices $A$ and $B$ for the interview protocols.

\section{Ethical considerations}

Several considerations were made to ensure the protection of participants in this work. This was especially important given the power dynamics that can exist between instructor and student. $A$ member of the research team who had no prior interactions with the students in the course contacted them to solicit participation two weeks prior to the conclusion of the semester. This team member consented and interviewed the participants and transcribed the interviews afterward.Audio recordings were deleted upon verification of the transcripts, which were identified only with pseudonyms. The race and gender of participants were not collected due to the small class sizes and the potential for these two factors alone to potentially "out" a participant. The instructor of the course only interacted with the data once it was in the form of de-identified transcripts, and no interviews were conducted until all final grades were posted for the course. Participants were given an information letter in lieu of an informed consent form since a signed consent form would be the only document linking them to the study, and this work was approved by the university's institutional review board.

\section{Positionality}

We made every attempt to remain unbiased and consider how our personal views and interactions would impact the study (Foote \& Bartell, 20I I). The team of researchers was structured as it was with expertise and positionality in mind. One member of the team taught the course and had expertise in research methodology.Another member of the team had not previously taught research methods courses, but had expertise in online instruction, as well as considerable experience with pre-service special education teachers. A third member of the team had considerable expertise with writing instruction and writing feedback. Our collective expertise made us a good team for this work, but it also allowed for different perspectives on the data during analysis. Had only the instructor of the course conducted this study, it might have been difficult for him to separate his desire for positive outcomes in his teaching from the findings in this study.

\section{Data analysis}

After the interviews were conducted and transcribed, we began analyzing our data. We followed a member checking protocol which allowed participants to review the transcripts of their individual interviews and provide us with feedback to ensure that we adequately and accurately captured their thoughts and viewpoints (Creswell, 1998; Maxwell, 2013). We used a hybrid coding approach for this analysis (Saldaña, 20I5), and transcripts were coded using Atlas.ti 7.5.18, a qualitative data analysis program that has been found to be similar to N-VIVO (Lewis, 2004). Codes were initially created to correspond to the seven points included in the writing feedback framework, as well as student perceptions of written and video-based feedback.Additional codes were created as necessary to reflect emerging themes in the data.Two members of the team coded the transcripts, and a third member acted as a reader.The team met to discuss discrepancies for interrater agreement and identified emerging themes. This process continued until all three researchers reached consensus. See Appendix $C$ for a list of sample codes used.

\section{FINDINGS}

Three themes emerged from the findings: (I) positive perception of video-based feedback; (2) video feedback was perceived to improve instructor social presence; and (3) student growth occurred as a result of the feedback and revision process used in the study. 


\section{Positive perception of video-based feedback}

Most participants indicated that they preferred the video feedback over the written feedback they received. One participant indicated that with the video feedback, he "was getting more specific feedback, perhaps better feedback." Another participant was a high school teacher who indicated that he was intrigued by the idea so much that he gave video-based feedback to his students for their next writing assignment to better understand it from both the perspective of the instructor, as well as the student. A couple of participants, however, indicated that they were intrigued by the video feedback, but preferred written feedback since it was a writing assignment. One participant found the written feedback to be "a lot more helpful... than the video. [She] definitely preferred the written feedback more."

\section{Video feedback and instructor social presence}

Participants often framed descriptions of their experiences with the feedback that they received in terms of the impact it had on instructor social presence in the course. Video feedback was perceived to improve instructor-student relationships. One participant described his experience this way: "In a lot of online courses... when you receive feedback it's just a very impersonal thing. I thought that the video feedback was... effective in terms of continuing that relationship you build with your professor.' Another participant also suggested that she "[preferred] the video in the context of building a relationship" with her instructor. The video feedback was also perceived positively because it afforded an avenue for emotional expression that is missing in communication that is only in writing. One participant described the video feedback as being "effective in the way it was able to convey information and meaning in the way you would only be able to get face-to-face." Another participant noted that "when you get feedback in writing it's very clinical, [non-emotional]... so to have that video was reassuring because [the instructor] started out with all positives." A third participant described the video feedback as being "more personal." All of the study's participants, including those who ultimately preferred written feedback, perceived the video feedback as being effective in terms of establishing instructor social presence in the course.

\section{Student growth and the revision process}

Participants described their growth as writers, especially as writers for research, as a result of the feedback and revision process that was employed in this pair of studies. One participant described her experience this way: "As a writer, I definitely grew. I didn't know a lot about this type of writing and the process that I had to go through to conduct a study. I definitely learned a lot." Another student discussed her growth in the context of her future educational undertakings, nothing that "after [her] revisions and getting support from [the instructor], the process made [her] realize that with support and feedback... [she] wanted to move forward and continue to grow." She noted that without the feedback and the opportunity to learn and grow from her mistakes, she would have learned much less in the course, and she might have reconsidered embarking on any future educational studies. Another student described this in terms of his previous professional experiences. "[The instructor's] outlook on the writing process... reflected real life, because if you turn in a less than stellar project... in [your] career, you're not going to be able to get away with leaving it as is. ... really appreciated [the prag- matism]." As a future K-12 teacher, this participant valued the iterative nature of the process. Another participant described the professor as leading her to "feel more confident than ever in [her] writing." She described her growth in terms of improved self-efficacy as a writer.

Several of the participants noted that they felt that they grew more in terms of their knowledge of the research process than they did as writers. One student described the feedback as being "focused more on the content than the craft [of writing.]" Another student noted that "the feedback really clarified a lot of concepts and things [she] didn't understand." Another student stated that he "[feels] like [he is] a better researcher now... without a doubt" because of the revision and feedback process embedded in the assignment. Overall, students felt that the feedback they received, and the revision process allowed them to grow as novice researchers and writers for research.

\section{DISCUSSION}

Receiving meaningful, personalized feedback is an important part of the learning process. However, how this feedback is given can dictate how it is received, or even if it is valued by students in the first place. Therefore, one of the most important findings from the current work was the impact video feedback had on student perceptions of the feedback they received. While written feedback often lacks tone, and students can insert their own negative tone when reading feedback that is critical of their work -even if that is not the instructor's intent (Taggart \& Laughlin, 2017), the video-based feedback was found to be personable and added a human element to the feedback process. As one student put it, "It's not like he was being a robot." Students who participated in this work indicated that the video-based feedback which included the instructor's tone, as well as other non-verbal cues, was found to be less threatening, and in many cases, students were more receptive to it as a result. This was consistent with research that has found audio and video feedback to be more supportive and easier to understand (e.g. Borup et al., 2014; Gould \& Day, 20I3; Parton et al., 2010 Thompson \& Lee, 20I2). Providing video feedback was more time consuming at first, and we suggest that instructors pursuing this for the first time initially allot additional time. However, by the end of the study, providing feedback in this manner took about the same amount of time as providing written feedback, and the perceived benefits made it a worthwhile endeavor.

Another critical finding from the current research is the positive impact video feedback had on student perceptions of their relationship with their instructor. Learning in an online context is challenging for many reasons, one of which is the disconnect between students and instructors in a digital space where they lack physical interactions (Petrides, 2002). However, providing video feedback in an online setting offers additional moments for the instructor to be seen as more than a name on a screen and/ or the sender of an email. It also offers an important opportunity for the provide personalized feedback that supports student satisfaction and academic performance (Pardo et al., 2019). Even if students find video feedback to be similar in value to written feedback, the increased connection and personalization might still make its implementation worthy of consideration. As the title of our work suggests, students found the video feedback to be an avenue for the instructor to humanize the learning experience, which can increase motivation to compelte assignments (Borup 
et al., 20I4; Harper et al., 20I2; Henderson \& Phillips, 20I5). Ultimately, using video feedback provided an opportunity to build relationships as well as make the content of the feedback more accessible to students, both of which are important elements for student learning and engagement in an online course.

All participants felt that they grew as practitioners and consumers of research as a result of the research proposal assignment and the feedback that they received; most saw this as the primary benefit of the feedback as opposed to improving their writing skills. For each of the students enrolled in this course, the research methods course was an outlier in their overall program of study. It was the only research design or statistics course that they took overall, and learning the research process, as well as how to write for research, was a challenge for many of them. We found it to be particularly important that students had an opportunity to revise and resubmit their work after receiving feedback on their writing. Research suggests that feedback should be actionable and providing students space to learn from their mistakes is vitally important, regardless of what type of feedback they receive. Several students were candid with us and explained that they would not have read the feedback they received at all if they found their initial grade to be satisfactory and did not have an opportunity to improve their work. As such, it becomes clear that providing students with revision opportunities is important for all writing assignments, including those where video-based feedback is utilized.

\section{LIMITATIONS AND FUTURE RESEARCH}

A limitation of this work is that it centers around student perceptions of the feedback they perceived, derived from interviews conducted after the full arc of a semester. During the semester, students had several interactions with the instructor aside from the feedback that they received on their research proposal, and it was difficult at times for participants to disentangle the overall course context from the feedback given on this assignment, even if it was a unique experience for them.

Conducting this study has improved learning outcomes for our students and has forced us to reflect on how we provide feedback for out students' writing products. Our desire to learn and grow in our own instructional practices was the genesis for this study. Future research should continue to explore different types of feedback, including audio- and video-based feedback, and this should be explored further in online and hybrid contexts. Providing writing feedback, particularly in online settings, is often a labor-intensive process (Wijeyewardene et al., 20I3), and any approaches that have the potential to provide quality feedback in a manner that saves instructors time are worthy of investigation. Finally, the larger context in which writing feedback is given, as well as other approaches to improve student-teacher relationships, should also be explored in future work.

\section{REFERENCES}

Agius, N.M., \& Wilkinson, A. (20|4). Students' and teachers' views of written feedback at undergraduate level:A literature review. Nurse Education Today, 34(4), 552559.

Broup, J.,West, R.E., Thomas, R., \& Graham, C. (20I4). Examining the impact of video feedback on instructor social presence in blended courses. International Review of Research in Open \& Distance, $(3),|-| 5$.

Carless, D. (2006). Differing perceptions in the feedback process.
Studies in Higher Education, 3 I (2), 219-233.

Collins, K., Groff, S., Mathena, C., \& Kupczynski, L. (2019).Asynchronous video and the development of instructor social presence and student engagement. Turkish Online Journal of Distance Education, 20(I), 53-70.

Conrad, S. M., \& Goldstein, L. M. (1999). ESL student revision after teacher-written comments: Text, contexts, and individuals. Journal of second language writing, 8(2), I47-I 79.

Creswell, J.W. (1998). Qualitative inquiry and research design: Choosing among five traditions. Thousand Oaks, CA: Sage.

Crookes, G., Davis, K.A., \& Caulk, N. (1994). Comparing teacher and student responses to written work. TESOL Quarterly, 28(I), $181-188$.

Cumming, A. (1985). Responding to the Writing of ESL Students. Highway One, 8, 58-78.

Ferris, D.R. (1997). The influence of teacher commentary on student revision. TESOL Quarterly, 3 I (2), 3 I 5-339.

Ferris, D. R. (2003). Response to student writing: Research implications for second language students. Mahwah, NJ: Erlbaum

Ferris, D. R., Liu, H., Sinha, A., \& Senna, M. (20I3).Written corrective feedback for individual L2 writers. Journal of Second Language Writing, 22(3), 307-329.

Ferris, D.R. (20।4). Responding to student writing:Teachers' philosophies and practices. Assessing Writing, 19, 6-23.

Foote, M.Q., \& Bartell, T.G. (20I I). Pathways to equity in mathematics education: How life experiences impact research positionality. Educational Studies in Mathematics, 78(I), 45-68.

Goldstein, L. M. (2004). Questions and answers about teacher written commentary and student revision:Teachers and students working together. Journal of Second Language Writing, I3(I), 63-80.

Gould, J., \& Day, P. (20I3). Hearing you loud and clear: Student perspectives of audio feedback in higher education. Assessment \& Evaluation in Higher Education, 38, 554-566.

Harper, F., Green, H., \& Fernandez-Toro, M. (2012, September). Evaluating the integration of Jing® screencasts in feedback on written assignments. In 2012 I5th International Conference on Interactive Collaborative Learning (ICL) (Pp. I-7). IEEE.

Hattie, J., \& Timperley, H. (2007). The power of feedback. Review of Educational Research, 77(I), 8I-I I 2.

Hattie, J. (2009). Visible learning:A synthesis of over 800 meta-analyses relating to achievement. Oxford, UK: Routledge.

Hattie, J. (20I2). Know they feedback. Feedback for Learning, 70(I), 18-23.

Henderson, M., \& Phillips, M. (20I5).Video-based feedback on student assessment: Scarily personal. Australasian Journal of Educational Technology, 3 I (I).

Higgins, R., Hartley, P., \& Skelton, A. (200I). Getting the message across: the problem of communicating assessment feedback. Teaching in Higher Education, 6(2), 269-274.

Holmes, K., \& Papageorgiou, G. (2008). Good, bad, and insufficient: Students' expectations, perceptions, and uses of feedback. Journal of Hospitality, Leisure, Sport \& Tourism, 8(I), 85-96.

Hyland, F., \& Hyland, K. (200I). Sugaring the pill: Praise and criticism in written feedback. Journal of Second Language Writing, 10(3), 185-212

Laflen, A., \& Smith, M. (20I7). Responding to the student writing online:Tracking student interactions with instructor feedback in a Learning Management System. Assessing Writing, 3 I, 
$39-52$.

Lee, I. (2008). Understanding teachers' written feedback practices in Hong Kong secondary classrooms. Journal of Second Language Writing, I 7(2), 69-85.

Lewis, R.B. (2004). NVivo 2.0 and ATLAS.ti 5.0:A comparative review of two popular qualitative data-analysis programs. Field Methods, I6(4), 439-469.

Lizzio, A., \&Wilson, K. (2008). Feedback on assessment; Students' perceptions of quality and effectiveness. Assessment \& Evaluation in Higher Education, 33(3), 263-275.

Li, J., \& De Luca, R. (20I4). Review of assessment feedback. Studies in Higher Education, 39(2), 378-393.

Liu, J., \& Hansen, J. G. (2002). Peer response in second language writing classrooms. Ann Arbor: University of Michigan Press.

Lowenthal, P. R. (20I5). A mixed methods examination of instructor social presence in accelerated online courses. In Kyei-Blankson, L., Blankson, J., Ntuli, E., \& Agyeman, C. (Eds). Handbook of Research on Strategic Management of Interaction, Presence, and Participation in Online Courses (Pp. 147-I59). Hershey, PA: IGI Global.

Mantello, M. (1997). Error correction in the L2 classroom. Canadian Modern Language Review, 54(I), I27-I3I.

Maxwell, J.A. (20I3). Qualitative research design:An interactive approach. (3rd ed.). Los Angeles: Sage Publications.

McCarthy, J. (20I5). Evaluating written, audio and video feedback in higher education summative assessment tasks. Issues in Educational Research, 25(2), 153.

McGrath, A.L., Taylor, A., \& Pychyl,T.A. (20I I).Writing helpful feedback:The influence of feedback type on students' perceptions and writing performance. The Canadian Journal for the Scholarship of Teaching and Learning, 2(2), 5.

Mertler, C.A. (20I8). Introduction to educational research (2nd ed.). Los Angeles: Sage Publications.

Myhill, D., \& Jones, S. (2007). More than just error correction: Students' perspectives on their revision processes during writing. Written Communication, 24(4), 323-343.

Oomen-Early, J., Bold, M.,Wiginton, K. L., Gallien, T. L., \& Anderson, N. (2008). Using asynchronous audio communication $(A A C)$ in the online classroom: A comparative study. Journal of Online Learning and Teaching, 4(3), 267-276.

Orsmond, P., Merry, S., \& Reiling, K. (2005). Biology students' utilization of tutors' formative feedback: a qualitative interview study. Assessment \& Evaluation in Higher Education, 30(4), 369-386.

Pardo,A., Jovanovic, J., Dawson, S., Gašević, D., \& Mirriahi, N. (2019). Using learning analytics to scale the provision of personalised feedback. British Journal of Educational Technology, 50(I), I28-I 38.

Parton, B. S., Crain-Dorough, M., \& Hancock, R. (20I0). Using flip camcorders to create video feedback: Is it realistic for professors and beneficial to students. International Journal of Instructional Technology \& Distance Learning, 7(I), I5-23.

Petrides, L.A. (2002). Web-based technologies for distributed (or distance) learning: Creating learning-centered educational experiences in the higher education classroom. International Journal of Instructional Media, 29(I), 69-77.

Poulos, A., \& Mahony, M.J. (2008). Effectiveness of feedback:The students' perspective. Assessment \& Evaluation in Higher Education, 33(2), I43-I54.

Price, M., Handley, K., Millar, J., \& O'donovan, B. (20I0). Feedback: all that effort, but what is the effect?. Assessment \& Evaluation in Higher Education, 35(3), 277-289.

Rowe, A. (20II). The personal dimension in teaching: Why students value feedback. International Journal of Educational Management, 25(4), 343-360.

Ryan, T., \& Henderson, M. (2018). Feeling feedback: Students' emotional responses to educator feedback. Assessment \& Evaluation in Higher Education, 43(6), 880-892.

Saldaa, J. (20I5). The coding manual for qualitative researchers. Los Angeles: Sage Publications.

Scott, D., Ribeiro, J., Burns, A., Danyluk, P., \& Bodnaresko, S. (2017). A review of the literature on academic writing supports and instructional design approaches within blended and online learning environments. Calgary: University of Calgary.

Sommers, N. (2006). Across the drafts. College Composition and Communication, 58(2), 248-257.

Taggart,A.R., \& Laughlin, M. (2017).Affect matters:When writing feedback leads to negative feeling. International Journal for the Scholarship of Teaching and Learning, I I (2), I-I I.

Thomas, R.A., West, R. E., \& Borup, J. (2017). An analysis of instructor social presence in online text and asynchronous video feedback comments. The Internet and Higher Education, 33, 6I-73.

Thompson, R., \& Lee, M. J. (20I2). Talking with students through screencasting: Experimentations with video feedback to improve student learning. The Journal of Interactive Technology \& Pedagogy, I ( I), I-I6.

van Beuningen, C. G., De Jong, N. H., \& Kuiken, F. (2008). The effect of direct and indirect corrective feedback on L2 learners' written accuracy.

Wallace, I., \& Moore, C. (20I2, January). Providing in-depth and personalized feedback to online students using audio recording. International Proceedings of Economics Development and Research, 27, 53-58.

Weaver, M.R. (2006). Do students value feedback? Student perceptions of tutors' written responses. Assessment \& Evaluation in Higher Education, 3 I (3), 379-394.

Wijeyewardene, Ingrid, H.P., \& Collins, M. (20I3). Against the odds:Teaching writing in an online environment. Journal of Academic Language \& Learning, 7(2), A20-A34.

Wolsey,T.D. (2008). Efficacy of instructor feedback on written work in an online program. International Journal on E-Learning, 7(2), 3 I I-329.

Wood, S.A. (20I2). Basic writers' perceptions of writing assessment practices. (Unpublished doctoral dissertation). New Mexico State University, Las Cruces, New Mexico.

Zamel,V. (1985). Responding to student writing. Tesol Quarterly, I9(I), 79-101. 


\section{APPENDIX A}

\section{Semi-structured interview protocol 1}

I. Describe your process as a writer.
a.Where do you begin?
b. Role of revision?
c. Role of feedback?

2. What was your perception of the feedback that you received for your writing as a part of this course?

a. How feedback related to the revision process

b. General perception of feedback

c.Was it positive?

d.Was it timely?

e.Was it specific?

f.Was all of the feedback related to the assignment?

g.Was the feedback in line with the assessment criteria spelled out in the rubric?

3. How did the feedback and revision process used in this course impact your growth as a writer?

a. Did the feedback have a developmental focus?

b. If you were not permitted to revise each section, how would that have changed the way you approached the assignment?

4. How similar or different was this process to previous graduate level writing experiences?

5. Do you have any additional comments that you would like to add? 


\section{APPENDIX B}

\section{Semi-structured interview protocol 2}

I. What was your perception of the feedback that you received for your writing as a part of this course?

a. General perception of feedback

i.Written

ii.Video

b. Did you prefer the written or video feedback? Can you elaborate on that?

c. How was the feedback related to the revision process?

d.Was all of the feedback related to the assignment?

e.Was the feedback positive?

2. How did the feedback and revision process used in this course impact your growth as a writer?

a. Did the feedback have a developmental focus?

b. If you were not permitted to revise each section, how would that have changed the way you approached the assignment?

3. How similar or different was this process to previous graduate level writing experiences?

a. Were revisions allowed?

b. Describe the type of feedback you have previously received.

4. Do you have any additional comments that you would like to share? 


\section{APPENDIX C}

\section{Selected Codes for Data Analysis}

\begin{tabular}{|c|c|c|}
\hline Code & Definition & Example in data \\
\hline FB_content & $\begin{array}{l}\text { Quotes related to the impact that } \\
\text { feedback and revision had on learning } \\
\text { course content }\end{array}$ & $\begin{array}{l}\text { "I was focused more on the content than the craft....and I think } \\
\text { the feedback was more related to the content." }\end{array}$ \\
\hline FB_growth & $\begin{array}{l}\text { Quotes related to the impact that } \\
\text { feedback had on student growth }\end{array}$ & $\begin{array}{l}\text { "[The feedback and revision process] did impact my growth } \\
\text { as a writer." }\end{array}$ \\
\hline FB_type & $\begin{array}{l}\text { Quotes related to the type of feedback } \\
\text { received on the research proposal }\end{array}$ & $\begin{array}{l}\text { "...there [were] some times that I would get written feedback } \\
\text { and not understand why [the instructor] would want some- } \\
\text { thing changed... and often times that was cleared up in the } \\
\text { video..." }\end{array}$ \\
\hline FB_type_videos & $\begin{array}{l}\text { Quotes related to the video-based } \\
\text { feedback received on the research } \\
\text { proposal }\end{array}$ & $\begin{array}{l}\text { "I would say it was interesting in terms of getting video feed- } \\
\text { back. That's not something that l've ever gotten in any of my } \\
\text { courses..." }\end{array}$ \\
\hline FB_type_written & $\begin{array}{l}\text { Quotes related to the written feed- } \\
\text { back received on the research propos- } \\
\text { al }\end{array}$ & $\begin{array}{l}\text { "I would say that the written feedback was typical of other } \\
\text { written feedback that I have received..." }\end{array}$ \\
\hline $\begin{array}{l}\text { FW_develop_ } \\
\text { focused }\end{array}$ & $\begin{array}{l}\text { Part of revision framework; Feedback } \\
\text { was oriented towards student growth } \\
\text { and development; formative instead of } \\
\text { summative }\end{array}$ & $\begin{array}{l}\text { “... [the feedback] wasn't leading me to where I should be, it } \\
\text { was... helping me find my way... It wasn't like holding your } \\
\text { hand through the process." }\end{array}$ \\
\hline FW_positive & $\begin{array}{l}\text { Part of revision framework; Feedback } \\
\text { included both positive comments and } \\
\text { constructive criticism }\end{array}$ & $\begin{array}{l}\text { "[The feedback was] very positive, critical, honest, and just very } \\
\text { straight forward..." }\end{array}$ \\
\hline FW_relevant & $\begin{array}{l}\text { Part of revision framework; Feedback } \\
\text { was relevant to the assignment and } \\
\text { aligned with the assignment rubric }\end{array}$ & $\begin{array}{l}\text { "...I feel like the wording that was used in the... feedback } \\
\text { matched what was in the rubric....I think that they were very } \\
\text { much in line with each other." }\end{array}$ \\
\hline $\mathrm{EE}$ & $\begin{array}{l}\text { Quotes related to emotional expres- } \\
\text { sion, including the expression of feel- } \\
\text { ings related to learning }\end{array}$ & $\begin{array}{l}\text { "... what I loved about the video is, when you get feedback } \\
\text { in writing it's very clinical, very non-emotional... so to have } \\
\text { that video was reassuring because he started out with all the } \\
\text { positives." }\end{array}$ \\
\hline ISR & $\begin{array}{l}\text { Quotes related to instructor-student } \\
\text { relationships }\end{array}$ & $\begin{array}{l}\text { “...[I] saw value in creating relationships. The video feedback } \\
\text { was helpful in creating the relationship between instructor } \\
\text { and student, especially in a hybrid course." }\end{array}$ \\
\hline OC & $\begin{array}{l}\text { Quotes related to open communica- } \\
\text { tion, including recognition of individual } \\
\text { contributions and developmentally-fo- } \\
\text { cused feedback }\end{array}$ & $\begin{array}{l}\text { “... [the instructor] was very personable with the class. He was } \\
\text { very down to earth. He acted like he cared.... guess he came } \\
\text { off that way; it made people want to work harder for him." }\end{array}$ \\
\hline RP & $\begin{array}{l}\text { Quotes related to the instructor's abil- } \\
\text { ity to be perceived as a "real person" }\end{array}$ & $\begin{array}{l}\text { "“...if something needed to be modified, he understood. It's not } \\
\text { likeee he was... being a robot. He was very humanized." }\end{array}$ \\
\hline W_research & $\begin{array}{l}\text { Quotes related to how student under- } \\
\text { standing of the research process was } \\
\text { impacted }\end{array}$ & $\begin{array}{l}\text { "As a writer I believe I feel more comfortable with attacking } \\
\text { research now; as I said, I gained a greater respect for research- } \\
\text { ers." }\end{array}$ \\
\hline vision & Quotes related to the revision process & $\begin{array}{l}\text { "“...the revisions were just invaluable... I feel like I am a better } \\
\text { researcher now because of this course.” }\end{array}$ \\
\hline
\end{tabular}

